\title{
Comprehensive Two-Dimensional Separation of Hydroxylated Polybrominated Diphenyl Ethers by Ultra-Performance Liquid Chromatography Coupled with Ion Mobility-Mass Spectrometry
}

\author{
Qiang Ma, ${ }^{1,2}$ Chao Wang, ${ }^{2}$ Hua Bai, ${ }^{2}$ Hai-Wei Xi, ${ }^{2}$ Guang-Cheng Xi, ${ }^{2}$ Xiao-Min Ren, ${ }^{1}$ \\ Yu Yang, ${ }^{1}$ Liang-Hong Guo ${ }^{1}$
}

${ }^{1}$ State Key Laboratory of Environmental Chemistry and Ecotoxicology, Research Center for Eco-Environmental Sciences, Chinese Academy of Sciences, Beijing 100085, China

${ }^{2}$ Chinese Academy of Inspection and Quarantine, Beijing 100123, China

\begin{abstract}
A comprehensive two-dimensional system coupling ultra-performance liquid chromatography (UPLC) and ion mobility-mass spectrometry (IM-MS) has been applied for the separation and analysis of hydroxylated polybrominated diphenyl ethers (OH-PBDEs). A complex mixture containing $23 \mathrm{OH}-\mathrm{PBDE}$ congeners ranging from hydroxylated monobromodiphenyl ether $(\mathrm{OH}-$ monoBDE) to hydroxylated octabromodiphenyl ether (OH-octaBDE) was satisfactorily separated within 16 min of analysis time. The first-dimensional reversed-phase UPLC was performed on a sub-2 $\mu \mathrm{m} \mathrm{BEH} \mathrm{C}_{18}$ chromatographic column using acetonitrile-water gradient elution program with a flow rate ramp. It enabled excellent chromatographic separation for both between-class and within-class OH-PBDEs based on their differences in hydrophobicity. Following the preionization resolution in the first dimension, the second-dimensional IM-MS employed a hybrid electrospray quadrupole ion mobility time-of-flight mass spectrometer and added an extra postionization separation for between-class OH-PBDE congeners on account of their relative mobility disparity during a very short period of $8.80 \mathrm{~ms}$. The orthogonality of the developed twodimensional system was evaluated with the correlation coefficient of 0.9665 and peak spreading angle of $14.87^{\circ}$. The peak capacity of the system was calculated to be approximately 2 and 15 times higher than that of the two dimensions used alone, respectively. The two-dimensional separation plane also contributed to the removal of background interference ions and the enhanced confidence in the characterization of OH-PBDEs of interest.
\end{abstract}

Key words: Hydroxylated polybrominated diphenyl ethers, Ultra-performance liquid chromatography, Ion mobility-mass spectrometry, Two-dimensional separation

Electronic supplementary material The online version of this article (doi:10.1007/s13361-011-0200-2) contains supplementary material, which is available to authorized users.

Correspondence to: Liang-Hong Guo; e-mail: LHGuo@rcees.ac.cn

\section{Introduction}

$\mathrm{B}$ rominated flame retardants (BFRs) are a diverse group of industrial chemicals widely used in a vast amount of consumer products for the purpose of fire prevention and resistance, which typically include hexabromocyclododecane (HBCD), tetrabromobisphenol A (TBBPA), polybrominated 
biphenyls (PBBs), and polybrominated diphenyl ethers (PBDEs) [1, 2]. Among them, PBDEs are an important class of additive BFRs, produced by brominating diphenyl ethers in the presence of a catalyst, and are mainly applied to furniture foam, textile coatings, consumer electronics, wire and cable insulation, plastics for personal computers and small appliances, etc. [3]. The extensive use of the products containing BFRs like PBDEs has resulted in the release of these compounds to the environment during usage and disposal, and poses serious environmental and human risks. With the increasing concern about the potential hazard of PBDEs, as their structural analogues, hydroxylated polybrominated diphenyl ethers (OH-PBDEs) have been shown to bioaccumulate in abiotic environments, including surface water [4], precipitation [4] and sediment $[5,6]$, and organisms [6-11]. Laboratory studies support the emergence of certain OH-PBDEs as the resulting metabolites in rodents (rats or mice) [12, 13], fish [14], chickens [15], and humans [16] after exposure to parent PBDEs, whereas several OH-PBDE congeners have been reported to be isolated and structurally identified as natural products in marine sponges [17, 18], ascidians [19], tunicates [20], algae [21], and mussels [21]. Thus, the occurrence of OH-PBDEs may be originated from the uptake and metabolism of anthropogenic PBDEs and/or the accumulation of naturally existing compounds [22]. OH-PBDEs differ in biological effects compared with their precursor PBDEs, and there are indications that the exposure to OH-PBDEs may cause thyroid hormone transport and metabolism disorder [23, 24], neurotoxicity [25], cytotoxicity [26], and endocrine disruption [27, 28].

In order to evaluate the environmental distribution of $\mathrm{OH}-$ PBDEs, a number of papers have described analytical methods for the determination of OH-PBDEs, primarily focusing on gas chromatography (GC) coupled with electron capture detection (ECD) [7], low-resolution mass spectrometry (LRMS) [6-8, 21] operating in electron ionization (EI), chemical ionization (CI), or electron capture negative ionization (ECNI) mode, and sometimes high-resolution mass spectrometry (HRMS) $[4,6$, 9]. However, owing to OH-PBDEs' low volatility, a derivatization procedure via methylation or acetylation reaction is inevitably required, which may lead to several disadvantages: (1) low yield and loss of analytes arising from the timeconsuming derivatization protocol; (2) handling of highly toxic and carcinogenic derivatizing reagents (e.g., diazomethane); and (3) possible systematic quantitative errors due to differences in reaction kinetics for individual OH-PBDE congeners and structural isomers during derivatization.

Alternatively, mass spectrometry hyphenated with electrospray ionization (ESI), pneumatically assisted ion-spray ionization (ISP), or atmospheric pressure chemical ionization (APCI) interface has become preferred detection scheme following liquid chromatography (LC) for the analysis of OH-PBDEs [5, 29, 30]. The LC-based methodology has exhibited superiority in fulfilling direct determination of $\mathrm{OH}-$ PBDEs without tedious derivatization, making it a better choice than the GC-based approach. Nevertheless, only a very limited number of OH-PBDE congeners, confined to certain hydroxylated dibromodiphenyl ethers (OH-diBDEs), hydroxylated tribromodiphenyl ethers (OH-triBDEs), and hydroxylated tetrabromodiphenyl ethers (OH-tetraBDEs), were investigated in the aforementioned literatures. As hydroxylated substituents for PBDEs, OH-PBDEs theoretically cover 209 possible congeners, with a variation in bromine units as well as in structural isomerism. Given that their properties, toxicities, environmental occurrence, and fate may depend on structural details, a sensitive and specific analytical method is needed for their analysis. The challenge lies in the great complexity of the wide-ranging $\mathrm{OH}-\mathrm{PBDEs}$, making the separation and analysis difficult.

A two-dimensional separation is generally considered to be advantageous over its one-dimensional counterpart for resolving complex mixtures because of extended peak capacity and higher resolution. It is recommended that the two dimensions be connected in an on-line manner, referred to as a comprehensive two-dimensional separation, rather than in an off-line or heart-cut manner, in order to approach the ideal multiplicative total of peak capacity. To date, a broad range of separation techniques such as LC, GC, capillary electrophoresis (CE), and supercritical fluid chromatography (SFC) have been mutually interfaced to construct comprehensive two-dimensional separation systems [31-37]. Currently, LC in conjunction with ion mobility separation and MS measurement is becoming increasingly popular for complex mixture analysis, due to complementary separation steps and elevated peak capacity. The applications include the analysis for rat urinary metabonome [38], human plasma proteome [39], peptide mixtures [40, 41], pharmaceutical formulation [42], etc. The principle for ion mobility-mass spectrometry (IM-MS) has been described in detail elsewhere [43]. Briefly, IM-MS is a gas-phase electrophoretic technique that allows ionized target molecules to be separated on the basis of their mobility in the presence of an inert carrier gas and under the influence of a weak electric field. The system incorporating ion mobility separation in tandem with LC and MS enables the initial separation of components by LC, then transfers and disperses the ions generated in the ion source according to their differing mobility, and finally records their mass-tocharge ratio $(\mathrm{m} / \mathrm{z})$ by a time-of-flight (TOF) mass analyzer.

The introduction of ultra-performance liquid chromatography (UPLC), harnessing chromatographic potential of sub$2 \mu \mathrm{m}$ packing particles, leads to significant improvements in terms of resolution, analysis speed, and detection sensitivity in comparison with traditional LC $[44,45]$. The advent of UPLC also reduces consumption of mobile phases and cost of analysis, and provides a great deal of green chemistry benefits [46]. A wide diversity of commercial stationary phases offers various options in selectivity for the analytes. Presumably, the hyphenation of UPLC as a replacement for conventional LC and IM-MS will perform even better for the separation and analysis of complex mixtures.

In this study, we have engaged in developing an effective two-dimensional tool combining UPLC and IM-MS (UPLC $\times$ IM-MS) for the analysis of $23 \mathrm{OH}-\mathrm{PBDE}$ homologues 
ranging from hydroxylated monobromodiphenyl ether $(\mathrm{OH}-$ monoBDE) to hydroxylated octabromodiphenyl ether $(\mathrm{OH}-$ octaBDE). The aim of the present work is to exploit the unique strength in the separation and characterization of OH-PBDEs by virtue of the developed comprehensive UPLC $\times$ IM-MS system.

\section{Experimental}

\section{Materials}

Authentic reference standards: (1) 2'-hydroxy-4-monobromodiphenyl ether (abbreviated name 2'-OH-BDE-3), (2) 3'hydroxy-2,4-dibromodiphenyl ether (3'-OH-BDE-7), (3) 4'hydroxy-2,2',4-tribromodiphenyl ether (4'-OH-BDE-17), (4) 3'-hydroxy-2,4,4'-tribromodiphenyl ether (3'-OH-BDE-28), (5) $2^{\prime}$-hydroxy-2,4,4'-tribromodiphenyl ether (2'-OH-BDE-28), (6) 4-hydroxy-2,2',3,4'-tetrabromodiphenyl ether (4-OH-BDE42), (7) 3-hydroxy-2,2',4,4'-tetrabromodiphenyl ether (3-OHBDE-47), (8) 4'-hydroxy-2,2',4,5'-tetrabromodiphenyl ether (4'-OH-BDE-49), (9) 6-hydroxy-2,2',4,4'-tetrabromodiphenyl ether (6-OH-BDE-47), (10) 2'-hydroxy-2,3',4,5'-tetrabromodiphenyl ether (2'-OH-BDE-68), (11) 3-hydroxy-2,2',4,4',6pentabromodiphenyl ether (3-OH-BDE-100), (12) 6-hydroxy2,2',3,3',4-pentabromodiphenyl ether (6-OH-BDE-82), (13) 4hydroxy-2,2',3,4',5-pentabromodiphenyl ether (4-OH-BDE90), (14) 4'-hydroxy-2,2',4,5,5'-pentabromodiphenyl ether (4'OH-BDE-101), (15) 5'-hydroxy-2,2',4,4',5-pentabromodiphenyl ether (5'-OH-BDE-99), (16) 6'-hydroxy-2,2',4,4',5pentabromodiphenyl ether (6'-OH-BDE-99), (17) 6-hydroxy2,2',3,4,4',5-hexabromodiphenyl ether (6-OH-BDE-137), (18) 3-hydroxy-2,2',4,4', 5',6-hexabromodiphenyl ether (3'-OHBDE-154), (19) 6-hydroxy-2,3,3',4,4',5'-hexabromodiphenyl ether (6-OH-BDE-157), (20) 4-hydroxy-2,2',3,4',5,6,6'-heptabromodiphenyl ether (4-OH-BDE-188), (21) 6-hydroxy$2,2^{\prime}, 3,4,4^{\prime}, 5,5^{\prime}$-heptabromodiphenyl ether (6-OH-BDE-180), (22) 6-hydroxy-2,2',3,4,4',5, 6'heptabromodiphenyl ether (6OH-BDE-182), and (23) 4'-hydroxy-2,2',3,3',4,5',6,6'-octabromodiphenyl ether (4'-OH-BDE-201), all dissolved in acetonitrile with the concentration of 10 or $50 \mu \mathrm{g} / \mathrm{mL}$, were purchased from AccuStandard (New Haven, CT, USA). The nomenclature for OH-PBDEs in this paper followed the U.S. Environmental Protection Agency (EPA) numbering approach to simplify comparison with corresponding PBDE congeners [47]. Chemical structures of the OH-PBDE congeners involved in this study are shown in Scheme 1. Acetonitrile of LC-MS grade (J.T.Baker, Phillipsburg, NJ, USA) and Milli-Q ultrapure water (Millipore, Bedford, MA, USA) were employed as mobile phase constituents for UPLC separations.

\section{Instrumentation}

The UPLC separation was performed on an ACQUITY UPLC system (Waters, Milford, MA, USA) equipped with a binary solvent manager, a sample manager and a column heater. A Waters ACQUITY UPLC BEH $\mathrm{C}_{18}$ analytical column $(150 \mathrm{~mm} \times 2.1 \mathrm{~mm}, 1.7 \mu \mathrm{m})$, preceded by a Waters VanGuard pre-column $(5 \mathrm{~mm} \times 2.1 \mathrm{~mm}, 1.7 \mu \mathrm{m})$ of the same packing materials was used. The chromatographic elution was conducted with binary mobile phase gradient consisting of water (A) and acetonitrile (B). Initial gradient conditions were set to $63 \% \mathrm{~B}$ at the flow rate of $0.3 \mathrm{~mL} / \mathrm{min}$ before incorporating a linear gradient increasing to $68 \% \mathrm{~B}$ over $2 \mathrm{~min}$ and held for $3 \mathrm{~min}$. At $9 \mathrm{~min}$, the gradient was programmed to $75 \% \mathrm{~B}$. The gradient was then increased to $95 \% \mathrm{~B}$ and the flow rate was ramped to $0.5 \mathrm{~mL} / \mathrm{min}$ over $6 \mathrm{~min}$. At $16 \mathrm{~min}$, the gradient was returned to the initial conditions. The column temperature was maintained at $35{ }^{\circ} \mathrm{C}$. The samples were kept at $10{ }^{\circ} \mathrm{C}$ in the thermostated sample manager and a sampling volume of $10 \mu \mathrm{L}$ was injected for each run. The strong and weak needle wash solvents were $200 \mu \mathrm{L}$ of $100 \% \mathrm{~B}$ and $600 \mu \mathrm{L}$ of $63 \%$ B respectively.

The entire column eluent from UPLC was directed into a SYNAPT HDMS hybrid quadrupole ion mobility orthogonal acceleration time-of-flight mass spectrometer (Waters, Manchester, UK). The instrument was operated in electrospray negative-ion mode, enabling ionization of $\mathrm{OH}-\mathrm{PBDEs}$ with a capillary voltage of $3.0 \mathrm{kV}$ and a nitrogen desolvation gas flow rate of $400 \mathrm{~L} / \mathrm{h}$ at $350{ }^{\circ} \mathrm{C}$. A sampling cone voltage of $30 \mathrm{~V}$ and an extraction cone voltage of $4.0 \mathrm{~V}$ were set for the experiment. The quadrupole mass filter was run in the wide-band passthrough mode. The OH-PBDE ions were then accumulated into a trap ion guide region at the pressure of 0.03 mbar with argon trap collision energy set at $6.0 \mathrm{~V}$ and nitrogen trap gas flow rate of $1.5 \mathrm{~mL} / \mathrm{min}$. The ions were subsequently pulsed into an ion mobility drift cell over a period of $100 \mu$ s to undertake an ion mobility-based separation at 0.62 mbar. Each individual mobility experiment was $8.80 \mathrm{~ms}$ long with a $300 \mathrm{~m} / \mathrm{s}$ traveling wave amplitude at $8.0 \mathrm{~V}$ and a nitrogen mobility gas at the flow rate of $28 \mathrm{~mL} / \mathrm{min}$. The ions passing through the drift cell were then continually released to a transfer ion guide region with argon transfer collision energy set at $4.0 \mathrm{~V}$. Finally, the mobility-separated ions were conveyed to the reflection TOF mass analyzer operating in V-Optics mode whilst maintaining the temporal separation. Data were recorded over the range of $m / z 50$ to $1000 \mathrm{Da}$, with the repeated 1.0 -s scan time and 0.02-s inter-scan interval. The TOF mass analyzer was externally calibrated with a sodium formate solution. All analyses were acquired using an independent LockSpray reference sprayer infusing $200 \mathrm{ng} / \mathrm{mL}$ deprotonated leucine enkephalin solution $(\mathrm{m} / \mathrm{z} 554.2615 \mathrm{Da})$ at a flow rate of $5 \mu \mathrm{L} / \mathrm{min}$ to verify mass accuracy. Instrumentation control, data acquisition, and mining were carried out by MassLynx ver. 4.1 and DriftScope ver. 2.0 software supplied with the instrument (Waters, Manchester, UK).

\section{Results and Discussion}

\section{First-Dimensional Separation of $\mathrm{OH}-\mathrm{PBDES}$ by UPLC}

In this study, eight groups of OH-PBDE analogues individually substituted with one to eight bromine units were subject to the UPLC $\times$ IM-MS analysis. Additionally, there are sub-series of 
<smiles>Oc1ccccc1Oc1ccc(Br)cc1</smiles>

2'-OH-BDE-3 (1)<smiles>Oc1cccc(Oc2ccc(Br)cc2Br)c1</smiles>

3'-OH-BDE-7 (2)<smiles>Oc1ccc(Oc2ccc(Br)cc2Br)c(Br)c1</smiles>

4'-OH-BDE-17 (3)<smiles>Cc1ccc(Oc2ccc(I)c(O)c2)c(Br)c1</smiles>

3'-OH-BDE-28 (4)<smiles>Oc1cc(Br)ccc1Oc1ccc(Br)cc1Br</smiles>

2'-OH-BDE-28 (5)<smiles>Oc1ccc(Oc2ccc(Br)cc2Br)c(Br)c1Br</smiles><smiles>Oc1c(Br)ccc(Oc2ccc(Br)cc2Br)c1Br</smiles><smiles>Oc1cc(Br)c(Oc2ccc(Br)cc2Br)cc1Br</smiles><smiles>Oc1cc(Br)cc(Br)c1Oc1ccc(I)cc1Br</smiles><smiles>Oc1c(Br)cc(Br)cc1Oc1ccc(Br)cc1Br</smiles>

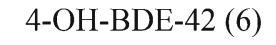
3-OH-BDE-47 (7) 4'-OH-BDE-49 (8) 6-OH-BDE-47 (9) 2'-OH-BDE-68 (10)<smiles>Oc1c(Br)cc(Br)c(Oc2ccc(Br)cc2Br)c1Br</smiles><smiles>Oc1cc(Br)c(Br)c(Br)c1Oc1cccc(Br)c1Br</smiles><smiles>Oc1c(Br)cc(Oc2ccc(Br)cc2Br)c(Br)c1Br</smiles>

3-OH-BDE-100 (11) 6-OH-BDE-82 (12) 4-OH-BDE-90 (13)<smiles>Oc1cc(Br)c(Oc2cc(Br)c(Br)cc2Br)cc1Br</smiles>
4-OH-BDE-101 (14)

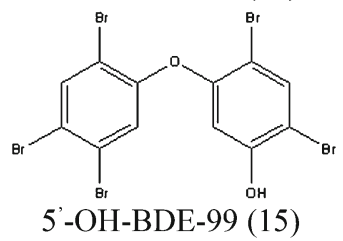<smiles>Oc1cc(Br)cc(Br)c1Oc1cc(Br)c(Br)cc1Br</smiles><smiles>Oc1c(Br)c(Br)c(Br)c(Br)c1Oc1ccc(Br)cc1Br</smiles><smiles>Oc1c(Br)cc(Br)c(Oc2cc(Br)c(Br)cc2Br)c1Br</smiles><smiles>Oc1cc(Br)c(Br)c(Br)c1Oc1cc(Br)c(Br)c(Br)c1</smiles>

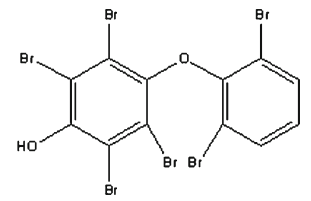

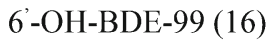
6-OH-BDE-137 (17)

6-OH-BDE-157 (19)

4-OH-BDE-188 (20)

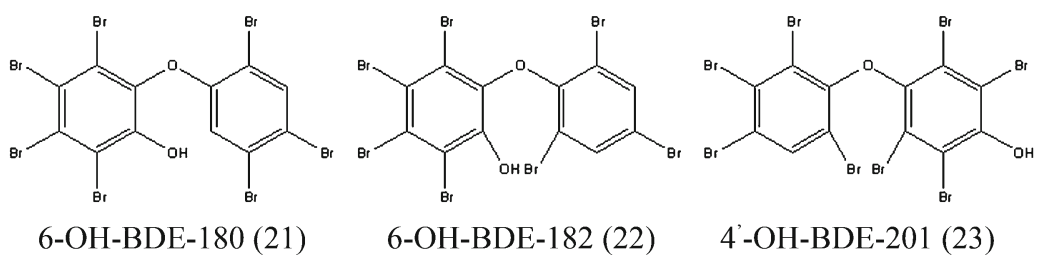

Scheme 1. Chemical structures of the $23 \mathrm{OH}-\mathrm{PBDE}$ compounds studied

isomeric species within certain OH-PBDE groups, specifically, three $\mathrm{OH}$-triBDE isomers, five OH-tetraBDE isomers, six isomers within hydroxylated pentabromodiphenyl ethers $(\mathrm{OH}-$ pentaBDEs), three isomers within hydroxylated hexabromodiphenyl ethers (OH-hexaBDEs), and three isomers within hydroxylated heptabromodiphenyl ethers (OH-heptaBDEs). The isomers distinguish from each other by the bromine substitution sites as well as the placement of single hydroxyl group, i.e., the location in the ortho-, meta-, or para-position relative to the diphenyl ether bridge. The compositional complexity of the analytes therefore poses a significant challenge for achieving both between-class and within-class separation for numerous OH-PBDE homologues and isomers.

In an attempt to explore the separation efficiency of sub$2 \mu \mathrm{m}$ particles, UPLC was configured in the instrumentation for the first dimension of separation in the present study. To achieve optimal band spacing for multicomponent $\mathrm{OH}-$ PBDEs, a systematic study of the parameters used to optimize chromatographic separation, such as stationary phase type, mobile phase composition, flow rate, and column temperature, was carried out. In view of the fact that the chemical nature of column packing materials may have a major effect on OH-PBDEs' chromatographic behavior, a wide diversity of commercially available UPLC columns based on high-pressure bearing ethylene bridged hybrid (BEH) particle substrate, such as $\mathrm{BEH} \mathrm{C}_{18}, \mathrm{C}_{8}$, Shield RP18, Phenyl, HILIC, and Amide, and high strength silica (HSS) particle substrate, such as $\mathrm{HSS} \mathrm{C}_{18}, \mathrm{C}_{18} \mathrm{SB}$, and T3 were investigated during the method development. The columns vary in functionalities, choice of covalently bonded silane reactions, completeness of bonding, presence or absence of endcapping, support surface area, pore size, carbon concentration, etc., and thereby exhibiting substantial differences in selectivity for the separation of OH-PBDEs. Table 1 summarizes various UPLC columns investigated.

In addition to the characteristics of column packing, selectivity may result from mobile phase composition as well. For this purpose, an integrated survey combining optimization of chromatographic columns plus mobile phase composition was conducted. Three water-miscible organic solvents commonly used in reversed-phase chromatography, i.e., acetonitrile, methanol, and tetrahydrofuran, were separately paired with water as the mobile phase for assessing the selectivity of serial OH-PBDEs on different columns (all with the dimension of $50 \mathrm{~mm} \times 2.1 \mathrm{~mm}$ ). The target $\mathrm{OH}-\mathrm{PBDE}$ congeners have a wide range of octanol/water partition coefficients $\log K_{o w}$ from 3.62 to 9.85 , calculated by an open source Estimation Program Interface (EPI) Suite ver. 4.0 software, indicating considerable disparity in hydrophobicity. To acquire satisfactory chromatographic resolution for $\mathrm{OH}-$ 
Table 1. Summary of Different Types of UPLC Columns Used in the Study

\begin{tabular}{|c|c|c|c|c|c|}
\hline Column & Bonding features & $\begin{array}{l}\text { Particle size } \\
\qquad(\mu \mathrm{m})\end{array}$ & $\begin{array}{l}\text { Pore size } \\
(\AA)\end{array}$ & $\begin{array}{l}\text { Surface Area } \\
\left(\mathrm{m}^{2} / \mathrm{g}\right)\end{array}$ & $\begin{array}{r}\text { Carbon } \\
\text { load }(\%)\end{array}$ \\
\hline BEH $\mathrm{C}_{18}$ & Trifunctional $\mathrm{C}_{18}$, fully endcapped, bonded to $\mathrm{BEH}$ particle substrate & 1.7 & 130 & 185 & 18 \\
\hline $\mathrm{BEH} \mathrm{C}_{8}$ & Trifunctional $\mathrm{C}_{8}$, fully endcapped, bonded to $\mathrm{BEH}$ particle substrate & 1.7 & 130 & 185 & 13 \\
\hline $\begin{array}{l}\text { BEH Shield } \\
\text { RP18 }\end{array}$ & $\begin{array}{l}\text { Monofunctional } \mathrm{C}_{18} \text { with polar group, fully endcapped, bonded to } \\
\text { BEH particle substrate }\end{array}$ & 1.7 & 130 & 185 & 17 \\
\hline BEH Phenyl & Trifunctional $\mathrm{C}_{6}$ phenyl, fully endcapped, bonded to $\mathrm{BEH}$ particle substrate & 1.7 & 130 & 185 & 15 \\
\hline BEH HILIC & Unbonded $\mathrm{BEH}$ particle substrate & 1.7 & 130 & 185 & - \\
\hline BEH Amide & Trifunctional amide, bonded to BEH particle substrate & 1.7 & 130 & 185 & 12 \\
\hline HSS $\mathrm{C}_{18}$ & High coverage trifunctional $\mathrm{C}_{18}$, fully endcapped, bonded to HSS particle substrate & 1.8 & 100 & 230 & 15 \\
\hline $\mathrm{HSS} \mathrm{C}_{18} \mathrm{SB}$ & $\begin{array}{l}\text { Intermediate coverage trifunctional } \mathrm{C}_{18} \text {, no endcapping, bonded to } \\
\text { HSS particle substrate }\end{array}$ & 1.8 & 100 & 230 & 8 \\
\hline HSS T3 & $\mathrm{T} 3\left(\mathrm{C}_{18}\right)$ bonding and endcapping, bonded to HSS particle substrate & 1.8 & 100 & 230 & 11 \\
\hline
\end{tabular}

PBDE homologues in a reasonable period of time, a gradient elution program was applied. For each particular type of column, the optimum initial solvent strength and gradient elution condition were carefully adjusted to obtain utmost retention and separation under the circumstance. Since ESI ionization occurs in solution state, mobile phase composition may affect ionization efficiency and detection sensitivity of the solutes. For this reason, both chromatographic performance and mass spectrometric sensitivity were taking into account to determine the optimal protocol. Experimental results demonstrated that selectivity was quite different from column to column and even for the same column when matched with different mobile phases. BEH HILIC and Amide columns were not effective in resolving OH-PBDEs and the compounds all emerged into one coeluting peak. BEH $\mathrm{C}_{18}$ column together with acetonitrile-water mobile phase gave maximum resolution and sensitivity for the mixture of OH-PBDE compounds by visual inspection. UPLC also favors acetonitrile as the organic part of mobile phase in terms of lower viscosity, which is beneficial to alleviating column backpressure caused by sub- $2 \mu \mathrm{m}$ packing particles. Afterwards, the OH-PBDEs mixture was eluted on the BEH $\mathrm{C}_{18}$ column with mobile phases consisting of acetonitrile paired with various buffer solutions adjusted to varying $\mathrm{pH}$ values within appropriate buffer range: aqueous $5 \mathrm{mM}$ ammonium formate (adjusted to $\mathrm{pH}$ value of $2.5,3.0$, and 3.5 with formic acid, respectively), aqueous $5 \mathrm{mM}$ ammonium acetate (adjusted to $\mathrm{pH}$ at 4.0, 4.5, 5.0, 5.5, and 6.5 with acetic acid, respectively), aqueous $5 \mathrm{mM}$ ammonium bicarbonate (adjusted to $\mathrm{pH}$ at 8.0, 8.5, 9.0, 9.5, 10.0, 10.5, and 11.0 using ammonia, respectively). The obtained chromatograms revealed that the addition of buffer solution lead to serious deterioration in chromatographic peak shape for some OH-PBDE congeners in comparison with those without buffer. Given the optimum stationary phase type and mobile phase composition, $\mathrm{BEH} \mathrm{C}_{18}$ columns with the same inner diameter and particle size, but differing lengths $(50,100$, and $150 \mathrm{~mm}$ ) were further compared. It was observed that $\mathrm{OH}-$ PBDEs, especially within-class structural isomers, were better resolved on the column of $150 \mathrm{~mm}$, with the average resolution of 1.35 , which was 1.67 times higher than that of $50 \mathrm{~mm}$ and 1.15 times higher than that of $100 \mathrm{~mm}$.
The influence of mobile phase flow rate within the range from 0.2 to $0.6 \mathrm{~mL} / \mathrm{min}$ on the separation of OH-PBDEs was evaluated. The optimal resolution of adjacent isomers within $\mathrm{OH}$-triBDEs, OH-tetraBDEs, OH-pentaBDEs, and OH-hexaBDEs was achieved at the flow rate of $0.3 \mathrm{~mL} / \mathrm{min}$, with the mean resolution being $0.41,1.24,0.99$, and 1.16 , respectively. One remark is that the elevation of flow rate preferably benefits the separation of OH-heptaBDEs isomers, and the best resolution was measured to be 0.60 at the flow rate of $0.4 \mathrm{~mL} / \mathrm{min}$. Hence, a flow rate ramp was utilized during the last phase of gradient elution to improve the resolution for OH-heptaBDEs isomers. Although a change in temperature is less effective as a means of altering selectivity in most cases, the band spacing for $\mathrm{OH}-$ hexaBDE structural isomers changed slightly when column temperature was varied from $30{ }^{\circ} \mathrm{C}$ to $55^{\circ} \mathrm{C}$ in our study, amongst which $35{ }^{\circ} \mathrm{C}$ presented an optimum average resolution of 1.16 for $\mathrm{OH}$-hexaBDE isomers.

After all the optimization experiments described above, the $23 \mathrm{OH}-\mathrm{PBDEs}$ were chromatographically separated by reversed-phase UPLC based on their differences in hydrophobicity. The total ion chromatogram of OH-PBDEs by the first-dimensional UPLC separation is shown in Figure 1a, with each OH-PBDE peak labeled with the same authentic reference standard number as described in the Materials section. The level of bromination played a dominating role in the separation of OH-PBDE homologues. OH-monoBDE with the lowest hydrophobicity was eluted earliest in the chromatogram with the retention factor $\mathrm{k}^{\prime}$ of 0.84 , while $\mathrm{OH}$-octaBDE with the highest hydrophobicity was eluted towards the end with the retention factor $\mathrm{k}^{\prime}$ of 7.68 . The vast majority of within-class structural isomers of OH-PBDEs were well resolved according to slight difference in hydrophobicity, except that only minor overlaps between two pairs of isomers (4'-OH-BDE-17 and 3'-OH-BDE-28, both from $\mathrm{OH}$-triBDEs, with the resolution of 0.25 ; 4'-OH-BDE101 and 5'-OH-BDE-99, both from OH-pentaBDEs, with the resolution of 0.10$)$ and between two congeners $(2$ '-OHBDE-68 from OH-tetraBDEs and 3-OH-BDE-100 from OHpentaBDEs, with the resolution of 0.25 ) appeared. The retention times and resolutions for the OH-PBDEs are shown in Table 2. 

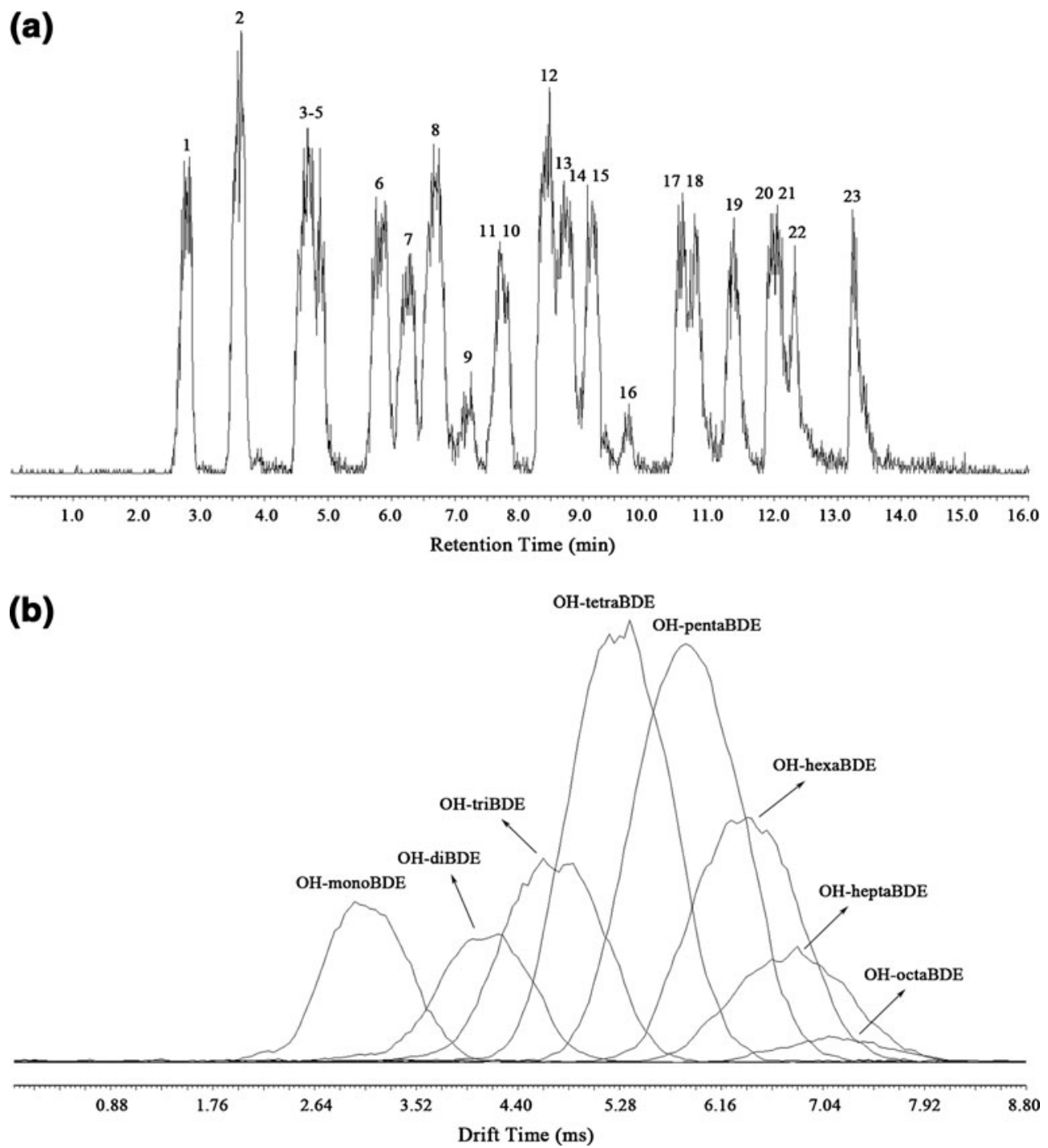

Figure 1. (a) Total ion chromatogram for OH-PBDE mixture solution at a concentration of $5 \mu \mathrm{g} / \mathrm{mL}$ by UPLC separation, analyzed on a BEH $\mathrm{C}_{18}$ column $(150 \mathrm{~mm} \times 2.1 \mathrm{~mm}, 1.7 \mu \mathrm{m})$ preceded by a VanGuard BEH $\mathrm{C}_{18}$ pre-column $(5 \mathrm{~mm} \times 2.1 \mathrm{~mm}$, $1.7 \mu \mathrm{m})$; mobile phase: acetonitrile-water gradient elution with a flow rate ramp program; column temperature: $35^{\circ} \mathrm{C}$. (b) lon mobility chromatogram for directly infused OH-PBDE mixture solution at a concentration of $5 \mu \mathrm{g} / \mathrm{mL}$ by ion mobility separation. $\mathrm{OH}-\mathrm{PBDEs}$ ions were generated by ESI operating in negative mode and then subjected to an ion mobility separation with nitrogen mobility gas flow rate of $28 \mathrm{~mL} / \mathrm{min}$, mobility wave velocity of $300 \mathrm{~m} / \mathrm{s}$ and mobility wave height of $8.0 \mathrm{~V}$. The mass spectra were collected by a TOF mass analyzer running in V-Optics mode from $\mathrm{m} / \mathrm{z} 50$ to $1000 \mathrm{Da}$, with a scan time of $1.0 \mathrm{~s}$ and an inter-scan interval of $0.02 \mathrm{~s}$

\section{Second-Dimensional Separation of OH-PBDEs by $I M-M S$}

Following the first-dimensional pre-ionization resolution of OH-PBDEs afforded by UPLC, the whole chromatographic eluting $\mathrm{OH}-\mathrm{PBDE}$ species underwent further second-dimensional post-ionization ion mobility separation in an on-line manner without diminishing the fidelity of the first dimension of separation. Initial studies aiming at optimizing a series of MS parameters and ion mobility separation conditions were performed by infusing the OH-PBDE mixture solution into the ESI ion source of the spectrometer using an integrated syringe pump. IM-MS gas flow rate demonstrated great impact on ion mobility separation of $\mathrm{OH}-\mathrm{PBDEs}$. By varying the IM-MS gas flow rate from 5 to $40 \mathrm{~mL} / \mathrm{min}$ to examine its effect on the ion mobility data acquired, a flow rate of $28 \mathrm{~mL} / \mathrm{min}$ appropriately allowed all OH-PBDE ions to traverse across the ion mobility drift tube during one pulse cycle. The optimum velocity and height of traveling wave were $300 \mathrm{~m} / \mathrm{s}$ and $8.0 \mathrm{~V}$, although variations in the wave velocity and height showed less impact on $\mathrm{OH}-$ PBDEs separation compared with the IM-MS gas flow rate in this experiment. The ion mobility chromatogram is shown in Figure 1b.

The OH-PBDE ions passed through the ion mobility gas with drift time being dependent on their mobility values, in 
this case, mainly on the basis of the degree of halogen substitution for diphenyl ether skeleton. The OH-PBDE compounds from $\mathrm{OH}-\mathrm{monoBDE}$ to $\mathrm{OH}$-octaBDE were broadly fractionated according to their collision crosssection disparity in gas phase. The rapid ion mobility separation was carried out during a very short period of $8.80 \mathrm{~ms}$ with the mean peak width at half height of $1.125 \mathrm{~ms}$ for OH-PBDEs. A $0.57-\mathrm{ms}$ average ion mobility drift time difference was observed for between-class OH-PBDEs from $\mathrm{OH}-\mathrm{monoBDE}$ to $\mathrm{OH}-\mathrm{octaBDE}$. The resolution for betweenclass OH-PBDEs by the second-dimensional ion mobility separation ranges from 0.10 (between $\mathrm{OH}$-heptaBDE and $\mathrm{OH}-\mathrm{octaBDE}$ ) to 0.57 (between $\mathrm{OH}-\mathrm{monoBDE}$ and $\mathrm{OH}-$ diBDE). A significant feature of the ion mobility separation for OH-PBDEs is that the associated millisecond ion mobility timescale $(8.80 \mathrm{~ms})$ is intermediate between the UPLC elution time (16 $\mathrm{min})$ and the microsecond detection time $(45 \mu \mathrm{s} / \mathrm{scan})$ required for TOF-MS. The ion mobility separation can therefore occur within one UPLC chromatographic peak with the mean peak width at half height of $13.2 \mathrm{~s}$, much narrower than that of conventional LC, while effectively feed components into TOF-MS very rapidly. The drift time and resolution for the OH-PBDEs are shown in Table 2.

The nested data set derived from the UPLC $\times$ IM-MS separation are demonstrated by three correlated visualized plots, i.e., drift time versus retention time plot (data summed over all $\mathrm{m} / \mathrm{z}$ values), $\mathrm{m} / \mathrm{z}$ versus retention time plot (data summed over all drift times) and $\mathrm{m} / \mathrm{z}$ versus drift time plot (data summed over all retention times). The band color reflects the signal intensity of the ions, with white representing the highest intensity and black the lowest intensity. As displayed in the drift time versus retention time plot (Figure 2), UPLC realized the first-dimensional separation for OH-PBDE congeners along the axis of retention time based on the differences in hydrophobicity, and IM-MS then achieved the second-dimensional separation along the axis of drift time based on the differences in ion mobility. Roughly, eight sections corresponding to each class of OH-PBDE homologues were observed in the drift time versus retention time plot. Each individual OH-PBDE peak visually located in the plot was characterized and labeled with corresponding reference number. OH-monoBDE with the smallest collision cross-sectional area drifted most rapidly through the mobility region, emerging in the lower left-hand part of the plot. OH-octaBDE moved towards the end due to the largest collision cross-sectional area, showing up in the upper right-hand part. Within-class OH-PBDE structural isomers also showed subtle differences in drifting trajectories. Maintaining the effects of separation on OH-PBDEs obtained by the first-dimensional UPLC, IMMS added a further separation for between-class $\mathrm{OH}$ PBDEs. On the other hand, with regard to the separation of within-class OH-PBDE isomers, IM-MS showed a weaker separation capability and with less variables to be optimized in comparison with UPLC. For the several pairs of structural isomers with limited resolution by UPLC, IMMS can hardly improve. Despite the relatively poor resolving power presumably due to the quite similar crosssectional areas for OH-PBDE structural isomers, with the addition of a second-dimensional ion mobility separation, the signals of OH-PBDE ions of interest can be precisely extracted from the complete data set for further analysis by the DriftScope software tool. Many of the ions with low

Table 2. Molecular Weights, $\log K_{\text {ow }}$, Retention Times, Drift Times and Resolutions of OH-PBDE Congeners

\begin{tabular}{|c|c|c|c|c|c|c|c|}
\hline OH-PBDE species & Compound & $\mathrm{M}_{\mathrm{w}}$ & $\log K_{o w}$ & $\begin{array}{l}\text { Retention time } \\
(\mathrm{min})\end{array}$ & $\begin{array}{l}\text { Resolution by } \\
\text { UPLC }\end{array}$ & $\begin{array}{l}\text { Drift time } \\
\quad(\mathrm{ms})\end{array}$ & $\begin{array}{l}\text { Resolution by } \\
\text { IM-MS }\end{array}$ \\
\hline OH-monoBDE & 2'-OH-BDE-3 & 263.9786 & 3.62 & 2.82 & - & 3.26 & - \\
\hline OH-diBDE & 3'-OH-BDE-7 & 341.8891 & 4.51 & 3.65 & 2.56 & 4.22 & 0.97 \\
\hline \multirow[t]{3}{*}{ OH-triBDE } & 4'-OH-BDE-17 & 419.7996 & 5.40 & 4.62 & 2.73 & 4.40 & 0.45 \\
\hline & 3'-OH-BDE-28 & & & 4.71 & 0.25 & 4.71 & \\
\hline & 2'-OH-BDE-28 & & & 4.91 & 0.56 & 5.02 & \\
\hline \multirow[t]{5}{*}{ OH-tetraBDE } & 4-OH-BDE-42 & 497.7101 & 6.29 & 5.84 & 2.33 & 5.24 & 0.53 \\
\hline & 3-OH-BDE-47 & & & 6.26 & 1.01 & 5.28 & \\
\hline & 4'-OH-BDE-49 & & & 6.68 & 0.97 & 5.37 & \\
\hline & 6-OH-BDE-47 & & & 7.20 & 1.31 & 5.32 & \\
\hline & 2'-OH-BDE-68 & & & 7.77 & 1.68 & 5.32 & \\
\hline \multirow[t]{6}{*}{ OH-pentaBDE } & 3-OH-BDE-100 & 575.6206 & 7.18 & 7.67 & 0.25 & 5.72 & 0.47 \\
\hline & 6-OH-BDE-82 & & & 8.41 & 1.64 & 5.81 & \\
\hline & 4-OH-BDE-90 & & & 8.75 & 0.72 & 6.03 & \\
\hline & 4'-OH-BDE-101 & & & 9.23 & 1.16 & 6.03 & \\
\hline & 5'-OH-BDE-99 & & & 9.26 & 0.10 & 5.76 & \\
\hline & 6'-OH-BDE-99 & & & 9.70 & 1.33 & 5.76 & \\
\hline \multirow[t]{3}{*}{ OH-hexaBDE } & 6-OH-BDE-137 & 653.5311 & 8.07 & 10.55 & 2.57 & 6.38 & 0.49 \\
\hline & 3'-OH-BDE-154 & & & 10.80 & 0.74 & 6.38 & \\
\hline & 6-OH-BDE-157 & & & 11.36 & 1.57 & 6.51 & \\
\hline \multirow[t]{3}{*}{ OH-heptaBDE } & 4-OH-BDE-188 & 731.4417 & 8.96 & 11.95 & 1.74 & 6.91 & 0.16 \\
\hline & 6-OH-BDE-180 & & & 12.10 & 0.49 & 6.60 & \\
\hline & 6-OH-BDE-182 & & & 12.32 & 0.71 & 6.95 & \\
\hline OH-octaBDE & 4'-OH-BDE-201 & 809.3522 & 9.85 & 13.28 & 3.18 & 7.22 & 0.16 \\
\hline
\end{tabular}




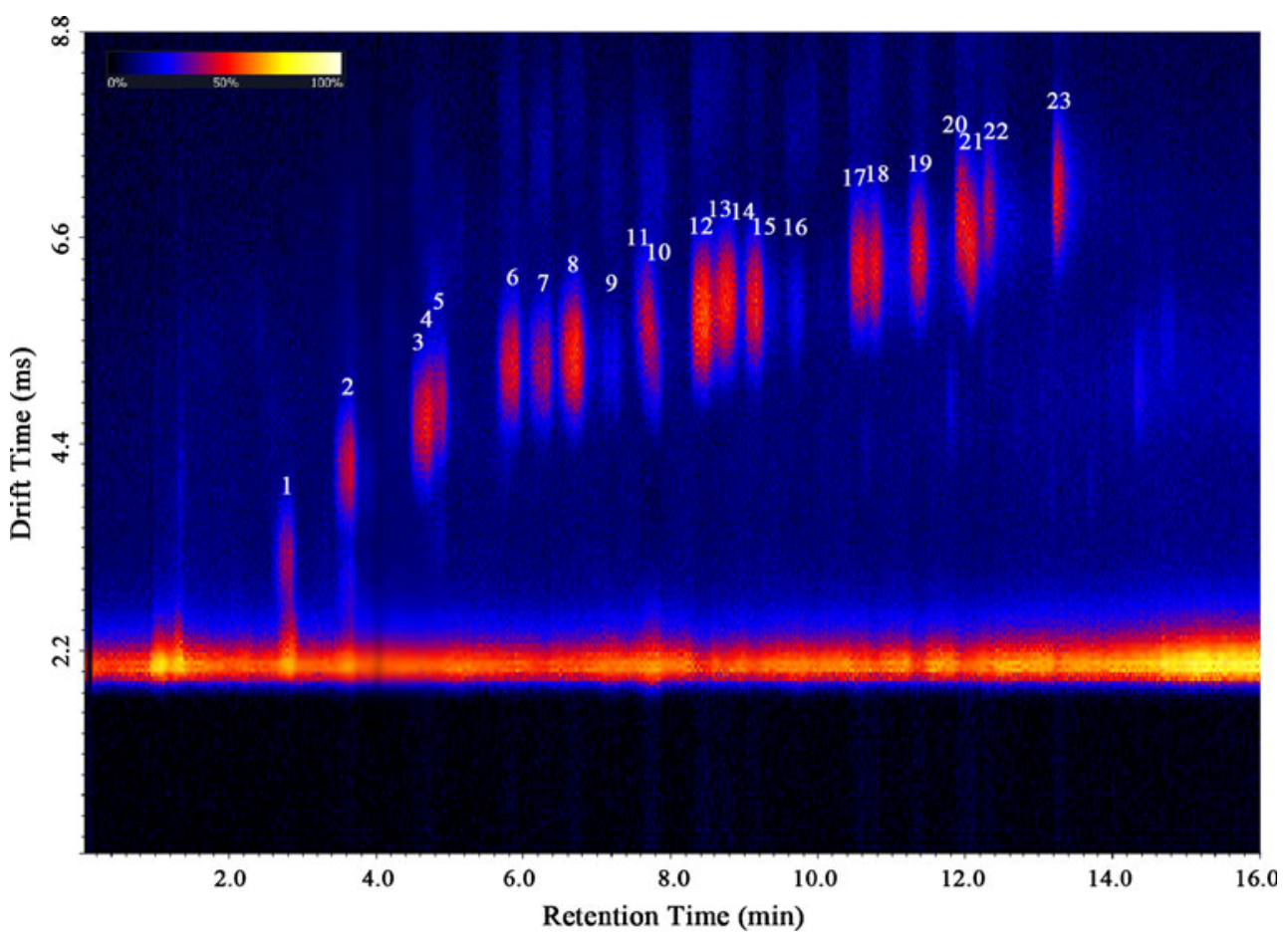

Figure 2. The drift time versus retention time plot of $\mathrm{OH}-\mathrm{PBDEs}$

molecular weight less than 200 Da normally traversed fastest with the drift time between 1.9 and $2.3 \mathrm{~ms}$. The OH-PBDE analytes can be discriminated from the aforementioned background interference ions, aiding in their interpretation and reducing the complexity of the data. A marked reduction in undesirable background noise is observed in Figure $3 b$.
The background-subtracted spectrum became quite apparent above the interfering substances. The mass spectrum was simplified for easier data interpretation and yielded improved signal-to-noise ratio, which was not available by LC-MS alone (Figure 3a). For instance, the characteristic ion peaks corresponding to $\mathrm{OH}-\mathrm{monoBDE}$ are clearly displayed

(a)

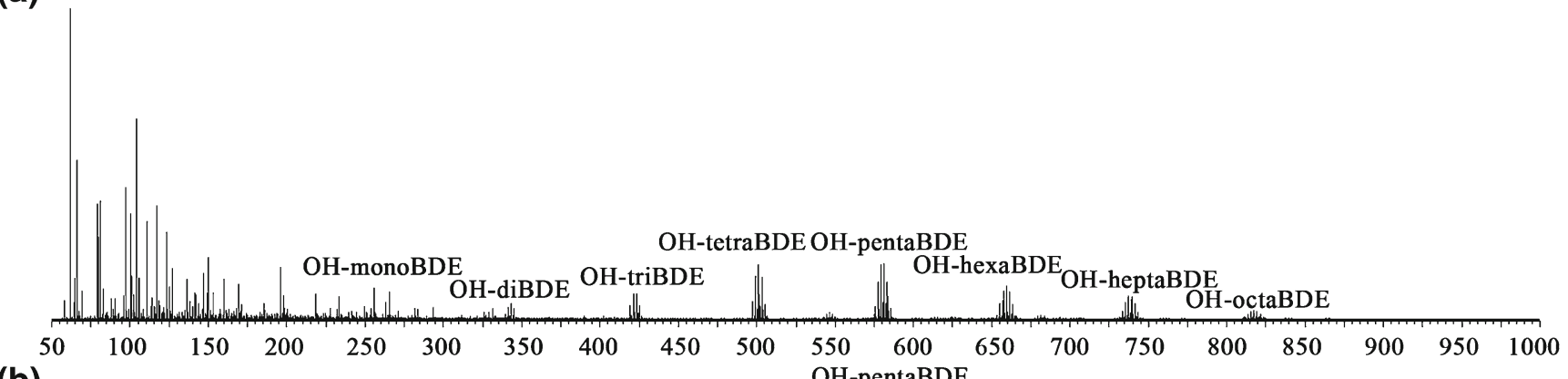

(b)

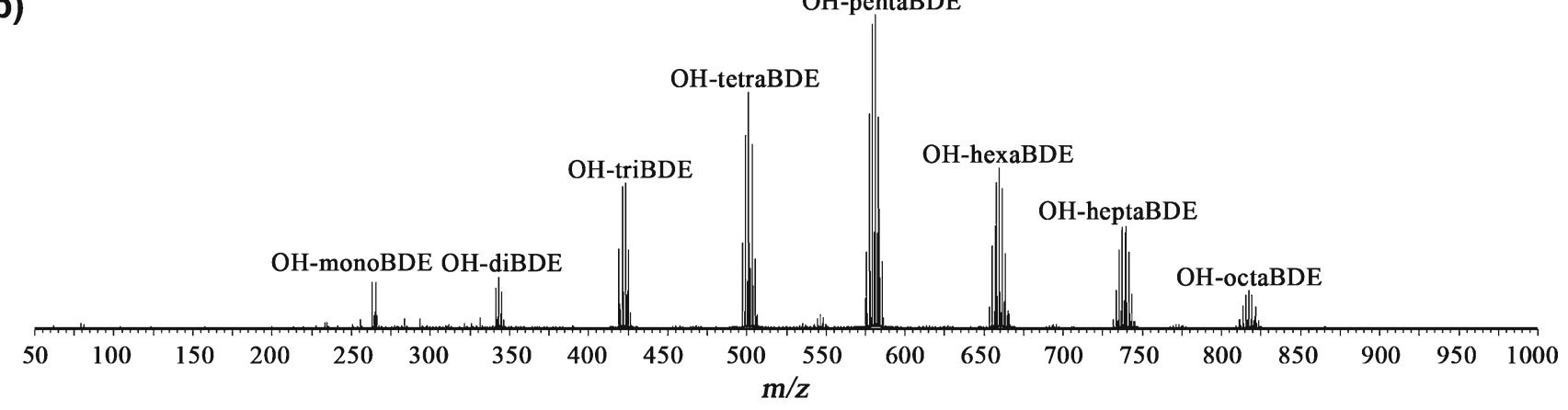

Figure 3. (a) Mass spectrum summed throughout the experiment without ion mobility separation (upper spectrum); and (b) Corresponding background-subtracted mass spectrum with ion mobility separation (lower spectrum) 


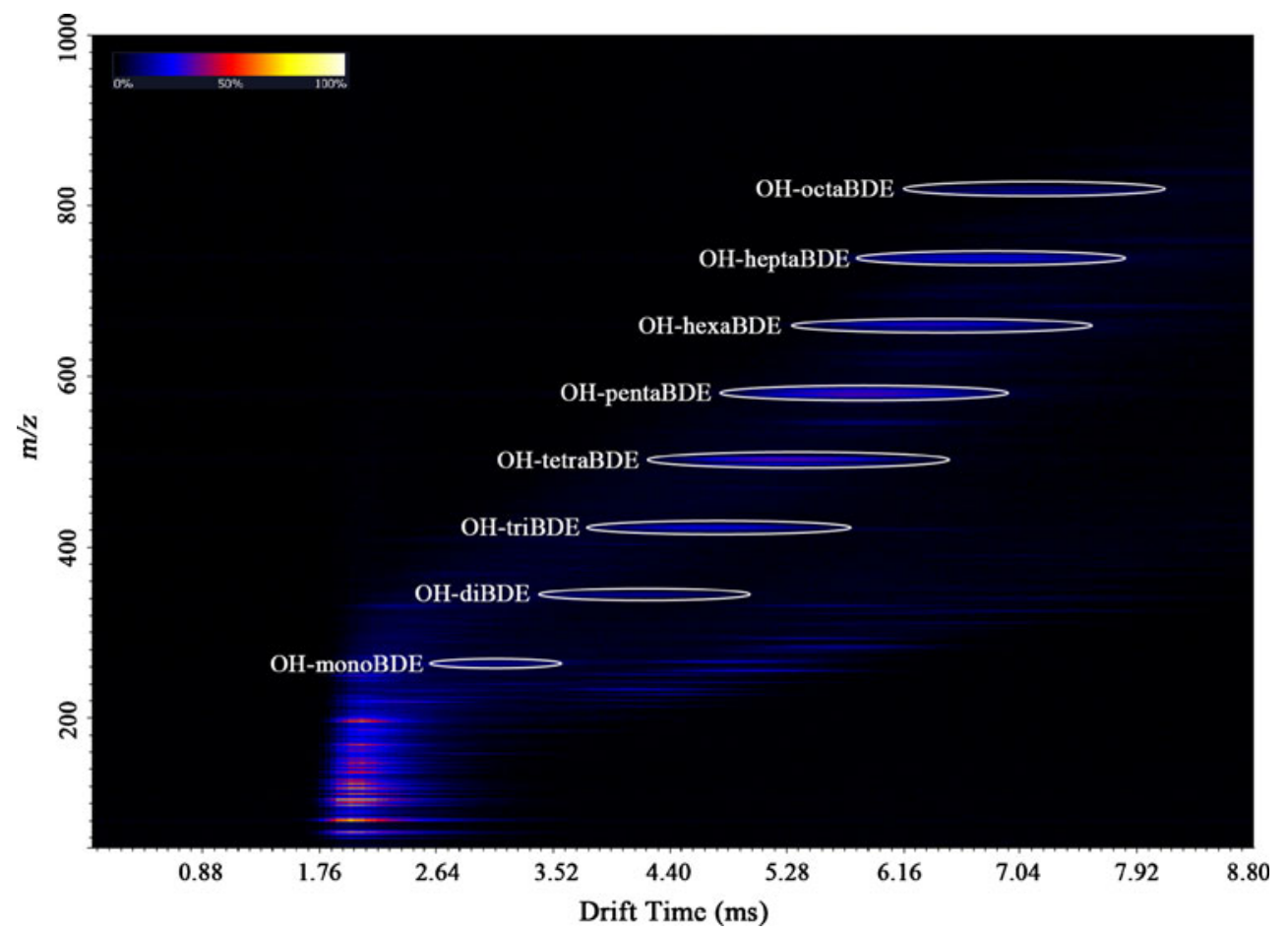

Figure 4. The $m / z$ versus drift time plot of OH-PBDEs

in Figure 3b, but almost not visible in Figure 3a. The quantitative enhancement in the signal-to-noise ratio was measured for certain representative OH-PBDE compounds based on the inclusion of ion mobility: the signal-to-noise ratio for 2'-OH-BDE-3 increased from 25.78 to $71.93,2.79$ times higher; 4-OH-BDE-42 increased from 16.73 to 62.57 , 3.74 times higher; 6-OH-BDE-157 increased from 12.12 to $52.48,4.33$ times higher. Furthermore, confidence in the identification and assignment of OH-PBDEs is enhanced by the presence of the ion of the correct $\mathrm{m} / \mathrm{z}$ at the expected ion mobility drift time and UPLC retention time associated with an OH-PBDE congener. A fast scanning TOF-MS enabled individual OH-PBDEs to be well identified by means of the dominant deprotonated pseudo-molecular ion peak obtained in the negative ESI mode. The presence of different numbers of bromines in OH-PBDEs was manifested by characteristic isotopic clusters of peaks in the mass spectra (Figure 3). The observed isotope cluster pattern as well as their relative abundance ratios matched well with the theoretical spectra simulated by an "isotope modeling" computing module embedded in the MassLynx software.

A well-defined set of spots in the shape of a flight of steps vertically scattered in regular equidistance are observed in the $\mathrm{m} / \mathrm{z}$ versus retention time plot (see Supplementary Material, which can be found in the electronic version of this article, Figure S1). Each step labeled in white ellipse represents a group of OH-PBDE congeners, which are evenly spaced in the mass distance of a bromine unit. The bottom stair stands for $\mathrm{OH}$ monoBDE, while the top stair for OH-octaBDE. Individual stair may be classified into horizontally adjacent subsections of well-separated within-class structural isomers. Some coeluting interferences with the same retention time as OH-PBDEs are observed in the plot. The ion mobility separation may offer the advantage in an extra dimensional separation for the target OH-PBDEs from the background interferences and realize the simplification of complex data. The information-rich $\mathrm{m} / \mathrm{z}$ versus retention time plot also confirmed that OH-PBDEs were eluted in the order of increasing bromine units by UPLC of first dimension. Figure 4 reveals the relationship between $\mathrm{m} / \mathrm{z}$ and drift time. Different bands corresponding to various classes of OH-PBDE homologues (in white ellipse) display ordered arrangements at different heights. Different classes of OH-PBDE homologues exhibit differing drifting velocities. The $\mathrm{OH}-$ PBDE ions with less bromines and lower mass carry higher mobility, thus, traverse faster across the drift region. The OH-PBDE analytes are also shown to be effectively isolated from the early-traveling components with the drift time between 1.76 and $2.64 \mathrm{~ms}$, leading to a reduction in background noise.

Table 3. The Calculated Correlation Coefficient and Peak Spreading Angle

\begin{tabular}{lcccccc}
\hline & \multicolumn{3}{c}{ Correlation coefficients $(r)$} & \multicolumn{3}{c}{ Peak spreading angle $(\beta$, deg) } \\
\cline { 2 - 7 } & UPLC & IM-MS & $\mathrm{M}_{\mathrm{w}}$ & UPLC & IM-MS & $\mathrm{M}_{\mathrm{w}}$ \\
\hline UPLC & 1.0000 & 0.9665 & 0.9780 & 0 & 14.87 & 12.05 \\
IM-MS & 0.9665 & 1.0000 & 0.9842 & 14.87 & 0 & 10.19 \\
$\mathrm{M}_{\mathrm{w}}$ & 0.9780 & 0.9842 & 1.0000 & 12.05 & 10.19 & 0 \\
\hline
\end{tabular}




\section{Evaluation on Orthogonality and Practical Peak Capacity of the UPLC $\times I M-M S$ System}

Orthogonality and peak capacity are interrelated parameters for estimating difference in selectivity or resolving power of a comprehensive two-dimensional system. Normally, orthogonality is dependent not only on the separation mechanism but also on the properties of the solutes and the separation conditions. According to the literature [48], factor analysis was utilized to quantitatively estimate the degree of UPLC $\times$ IM-MS separation orthogonality. Corrrelation coefficient ( $\mathrm{r}$ ) is a frequently used parameter to evaluate the orthogonality between the two dimensions. A perfect retention correlation is obtained when $\mathrm{r}=1$, and truly orthogonal separation is achieved when $r=0$. Most twodimensional separations lie between perfect correlation and perfect orthogonality. In our study, the r-value was calculated based on a correlation matrix incorporating the retention time and drift time of OH-PBDEs in the two dimensions, as well as their molecular weight (Table 2). The peak spreading angle $(\beta)$ between the retention axes in the orthogonal retention space was computed as the arc cosine value of $\mathrm{r}$. A value of $\beta$ close to $90^{\circ}$ indicates a nearly orthogonal separation. The calculated correlation coefficients and peak spreading angles are summarized in Table 3 , which reveal the similarity in retention behavior of $\mathrm{OH}-$ PBDE congeners between UPLC and IM-MS on the defined operational conditions. OH-monoBDE with the lowest hydrophobicity was eluted first in the first-dimensional UPLC, and also drifted fastest across the second-dimensional IM-MS due to the lowest mobility. On the other hand, $\mathrm{OH}$-octaBDE with the highest hydrophobicity and mobility undertook the longest retention in both dimensions. Because both retention vectors are strongly correlated with the extent of bromination of OH-PBDEs, i.e., their molecular weight, the UPLC $\times$ IM-MS separation is close to perfect correlation under the experimental conditions (see Supplementary Material, Figure S2).

The measured peak capacities for UPLC of the first dimension and IM-MS of the second dimension are 65 and 9, respectively, computed from the ratio of total retention time to mean peak width at half height in each dimension. Hence, the theoretical peak capacity for the UPLC $\times$ IM-MS plane is 585 . Based on the peak spreading angle of $14.87^{\circ}$, the experimentally derived peak capacity is calculated to be approximately 135. The actual peak capacity obtained from the comprehensive two-dimensional separation is, respectively, 2 and 15 times higher than those from the two dimensions used alone.

\section{Conclusions}

In this study, the developed UPLC $\times$ IM-MS system incorporating UPLC and IM-MS has demonstrated unique selectivity and improved peak capacity for the analysis of OH-PBDE compounds by making sufficient use of the twodimensional separation plane. The first-dimensional UPLC, as a pre-ionization separation technique, takes advantage of great separation efficiency originated from the sub-2 $\mu \mathrm{m}$ $\mathrm{BEH}$ particles and realizes excellent chromatographic resolution for both between-class and within-class OH-PBDE congeners. IM-MS, as a second-dimensional post-ionization separation technique, provides an additional rapid orthogonal means of separation for between-class OH-PBDEs according to their relative mobility. By virtue of the combination of UPLC and IM-MS, comprehensive isolation of 23 OH-PBDE congeners based on both hydrophobicity difference and mobility disparity has been achieved, with each separation dimension selective to a particular sample attribute. A fast scanning TOF-MS enables enough information to be acquired and recorded during the whole procedure. The UPLC $\times$ IM-MS system proves to be a feasible tool to well resolve OH-PBDE homologues, reduce mass spectral congestion and aid in the identification and characterization of OH-PBDEs.

\section{Acknowledgements}

The authors thank Mr. Yu-Chun Ge, Ms. Xiao-Fei Jia, and Mr. Yong Wang at Waters Corporation for their discussion on data interpretation. This work was financially supported by the National Natural Science Foundation of China (20890112, 20825519, 20921063), the National Basic Research Program of China (2011CB936001), the Science Research Program of General Administration of Quality Supervision, Inspection and Quarantine of China (2010IK088) and the Science Research Program of Chinese Academy of Inspection and Quarantine (2009JK016).

\section{References}

1. Alaee, M., Arias, P., Sjödin, A., Bergman, Å.: An Overview of Commercially Used Brominated Flame Retardants, Their Applications, Their Use Patterns in Different Countries/Regions, and Possible Modes of Release. Environ Int 29, 683-689 (2003)

2. Hakk, H., Letcher, R.J.: Metabolism in the Toxicokinetics and Fate of Brominated Flame Retardants - a Review. Environ Int 29, 801-828 (2003)

3. Hyötyläinen, T., Hartonen, K.: Determination of Brominated Flame Retardants in Environmental Samples. Trends Analyt Chem 21, 13-29 (2002)

4. Ueno, D., Darling, C., Alaee, M., Pacepavicius, G., Teixeira, C., Campbell, L., Letcher, R.J., Bergman, Å., Marsh, G., Muir, D.: Hydroxylated Polybrominated Diphenyl Ethers (OH-PBDEs) in the Abiotic Environment: Surface Water and Precipitation from Ontario. Canada Environ Sci Technol 42, 1657-1664 (2008)

5. Kato, Y., Okada, S., Atobe, K., Endo, T., Matsubara, F., Oguma, T., Haraguchi, K.: Simultaneous Determination by APCI-LC/MS/MS of Hydroxylated and Methoxylated Polybrominated Diphenyl Ethers Found in Marine Biota. Anal Chem 81, 5942-5948 (2009)

6. Lacorte, S., Ikonomou, M.G., Fischer, M.: A Comprehensive Gas Chromatography Coupled to High Resolution Mass Spectrometry Based Method for the Determination of Polybrominated Diphenyl Ethers and Their Hydroxylated and Methoxylated Metabolites in Environmental Samples. J Chromatogr A 1217, 337-347 (2010)

7. Malmvärn, A., Zebühr, Y., Kautsky, L., Bergman, Å., Asplund, L.: Hydroxylated and Methoxylated Polybrominated Diphenyl Ethers and Polybrominated Dibenzo- $p$-dioxins in Red Alga and Cyanobacteria Living in the Baltic Sea. Chemosphere 72, 910-916 (2008)

8. Verreault, J., Gabrielsen, G.W., Chu, S., Muir, D.C.G., Andersen, M., Hamaed, A., Letcher, R.J.: Flame Retardants and Methoxylated and 
Hydroxylated Polybrominated Diphenyl Ethers in Two Norwegian Arctic Top Predators: Glaucous Gulls and Polar Bears. Environ Sci Technol 39, 6021-6028 (2005)

9. Kelly, B.C., Ikonomou, M.G., Blair, J.D., Gobas, F.A.: Hydroxylated and Methoxylated Polybrominated Diphenyl Ethers in a Canadian Arctic Marine Food Web. Environ Sci Technol 42, 7069-7077 (2008)

10. Qiu, X., Bigsby, R.M., Hites, R.A.: Hydroxylated Metabolites of Polybrominated Diphenyl Ethers in Human Blood Samples from the United States. Environ Health Perspect 117, 93-98 (2009)

11. Yu, Z., Zheng, K., Ren, G., Zheng, Y., Ma, S., Peng, P., Wu, M., Sheng, G., Fu, J.: Identification of Hydroxylated Octa- and Nonabromodiphenyl Ethers in Human Serum from Electronic Waste Dismantling Workers. Environ Sci Technol 44, 3979-3985 (2010)

12. Marsh, G., Athanasiadou, M., Athanassiadis, I., Sandholm, A.: Identification of Hydroxylated Metabolites in 2,2',4,4'-Tetrabromodiphenyl Ether Exposed Rats. Chemosphere 63, 690-697 (2006)

13. Qiu, X., Mercado-Feliciano, M., Bigsby, R.M., Hites, R.A.: Measurement of Polybrominated Diphenyl Ethers and Metabolites in Mouse Plasma after Exposure to a Commercial Pentabromodiphenyl Ether Mixture. Environ Health Perspect 115, 1052-1058 (2007)

14. Kierkegaard, A., Burreau, S., Marsh, G., Klasson-Wehler, E., de Wit, C., Asplund, L.: Metabolism and Distribution of 2,2',4,4'-Tetrabromo $\left[{ }^{14} \mathrm{C}\right]$ Diphenyl Ether in Pike (Esox lucius) after Dietary Exposure. Organohalogen Compound 52, 58-61 (2001)

15. Hakk, H., Huwe, J.K., Murphy, K., Rutherford, D.: Metabolism of 2,2',4,4'-Tetrabromodiphenyl Ether (BDE-47) in Chickens. J Agric Food Chem 58, 8757-8762 (2010)

16. Athanasiadou, M., Cuadra, S.N., Marsh, G., Bergman, A., Jakobsson, K.: Polybrominated Diphenyl Ethers (PBDEs) and Bioaccumulative Hydroxylated PBDE Metabolites in Young Humans from Managua. Nicaragua Environ Health Perspect 116, 400-408 (2008)

17. Utkina, N.K., Denisenko, V.A., Virovaya, M.V., Scholokova, O.V., Prokofeva, N.G.: Two New Minor Polybrominated Dibenzo-p-dioxins from the Marine Sponge Dysidea dendyi.J Nat Prod 65, 1213-1215 (2002)

18. Hanif, N., Tanaka, J., Setiawan, A., Trianto, A., de Voogd, N.J., Murni, A., Tanaka, C., Higa, T.: Polybrominated Diphenyl Ethers from the Indonesian Sponge Lamellodysidea herbacea. J Nat Prod 70, 432-435 (2007)

19. Schumacher, R.W., Davidson, B.S.: Didemnolines A-D, New N9Substituted $\beta$-Carbolines from the Marine Ascidian Didemnum sp. Tetrahedron 51, 10125-10130 (1995)

20. Fu, X., Hossain, M.B., Schmitz, F.J., van der Helm, D.: Longithorones, Unique Prenylated Para- and Metacyclophane Type Quinones from the Tunicate Aplidium longithorax. J Org Chem 62, 3810-3819 (1997)

21. Malmvärn, A., Marsh, G., Kautsky, L., Athanasiadou, M., Bergman, Å., Asplund, L.: Hydroxylated and Methoxylated Brominated Diphenyl Ethers in the Red Algae Ceramium tenuicorne and Blue Mussels from the Baltic Sea. Environ Sci Technol 39, 2990-2997 (2005)

22. de Wit, C.A., Herzke, D., Vorkamp, K.: Brominated Flame Retardants in the Arctic Environment-Trends and New Candidates. Sci Total Environ 408, 2885-2918 (2010)

23. Meerts, I.A.T.M., van Zanden, J.J., Luijks, E.A.C., van Leeuwen-Bol, I., Marsh, G., Jakobsson, E., Bergman, A., Brouwer, A.: Potent Competitive Interactions of Some Brominated Flame Retardants and Related Compounds with Human Transthyretin in Vitro. Toxicol Sci 56, 95-104 (2000)

24. Kitamura, S., Shinohara, S., Iwase, E., Sugihara, K., Uramaru, N., Shigematsu, H., Fujimoto, N., Ohta, S.: Affinity for Thyroid Hormone and Estrogen Receptors of Hydroxylated Polybrominated Diphenyl Ethers. J Health Sci 54, 607-614 (2008)

25. Dingemans, M.M.L., de Groot, A., van Kleef, R.G.D.M., Bergman, Å., van den Berg, M., Vijverberg, H.P.M., Westerink, R.H.S.: Hydroxylation Increases the Neurotoxic Potential of BDE-47 to Affect Exocytosis and Calcium Homeostasis in PC12 Cells. Environ Health Perspect 116, 637-643 (2008)

26. Song, R., Duarte, T.L., Almeida, G.M., Farmer, P.B., Cooke, M.S., Zhang, W., Sheng, G., Fu, J., Jones, G.D.D.: Cytotoxicity and Gene Expression Profiling of Two Hydroxylated Polybrominated Diphenyl Ethers in Human H295R Adrenocortical Carcinoma Cells. Toxicol Lett 185, 23-31 (2009)

27. Meerts, I.A.T.M., Letcher, R.J., Hoving, S., Marsh, G., Bergman, Å., Lemmen, J.G., van der Burg, B., Brouwer, A.: In Vitro Estrogenicity of Polybrominated Diphenyl Ethers, Hydroxylated PBDEs, and Polybrominated Bisphenol A Compounds. Environ Health Perspect 109, 399407 (2001)
28. Cantón, R.F., Scholten, D.E.A., Marsh, G., de Jong, P.C., van den Berg, M.: Inhibition of Human Placental Aromatase Activity by Hydroxylated Polybrominated Diphenyl Ethers (OH-PBDEs). Toxicol Appl Pharmacol 227, 68-75 (2008)

29. Hua, W., Bennett, E.R., Letcher, R.J.: Triclosan in Waste and Surface Waters from the Upper Detroit River by Liquid ChromatographyElectrospray-Tandem Quadrupole Mass Spectrometry. Environ Int 31, $621-630(2005)$

30. Mas, S., Jáuregui, O., Rubio, F., de Juan, A., Tauler, R., Lacorte, S.: Comprehensive Liquid Chromatography-Ion-Spray Tandem Mass Spectrometry Method for the Identification and Quantification of Eight Hydroxylated Brominated Diphenyl Ethers in Environmental Matrices. J Mass Spectrom 42, 890-899 (2007)

31. Bushey, M.M., Jorgenson, J.W.: Automated Instrumentation for Comprehensive Two-Dimensional High-Performance Liquid Chromatography of Proteins. Anal Chem 62, 161-167 (1990)

32. Bushey, M.M., Jorgenson, J.W.: Automated Instrumentation for Comprehensive Two-Dimensional High-Performance Liquid Chromatography/Capillary Zone Electrophoresis. Anal Chem 62, 978-984 (1990)

33. Liu, Z., Phillips, J.B.: Comprehensive Two-Dimensional Gas Chromatography Using an On-Column Thermal Modulator Interface. $J$ Chromatogr Sci 29, 227-231 (1991)

34. Liu, Z., Ostrovsky, I., Farnworth, P.B., Lee, M.L.: Instrumentation for Comprehensive Two-Dimensional Supercritical Fluid-Gas Chromatography. Chromatographia 35, 567-573 (1993)

35. Quigley, W.W.C., Fraga, C.G., Synovec, R.E.: Comprehensive LC $\times$ GC for Enhanced Headspace Analysis. J Microcolumn Sep 12, 160-166 (2000)

36. Hirata, Y., Hashiguchi, T., Kawata, E.: Development of Comprehensive Two-Dimensional Packed Column Supercritical Fluid Chromatography. J Sep Sci 26, 531-535 (2003)

37. Michels, D.A., Hu, S., Dambrowtz, K.A., Eggertson, M.J., Lauterbach, K., Dovichi, N.J.: Capillary Sieving Electrophoresis-Micellar Electrokinetic Chromatography Fully Automated Two-Dimensional Capillary Electrophoresis Analysis of Deinococcus radiodurans Protein Homogenate. Electrophoresis 25, 3098-3105 (2004)

38. Harry, E.L., Weston, D.J., Bristow, A.W., Wilson, I.D., Creaser, C.S.: An Approach to Enhancing Coverage of the Urinary Metabonome Using Liquid Chromatography-Ion Mobility-Mass Spectrometry. $J$ Chromatogr B 871, 357-361 (2008)

39. Liu, X.Y., Valentine, S.J., Plasencia, M.D., Trimpin, S., Naylor, S., Clemmer, D.E.: Mapping the Human Plasma Proteome by SCX-LCIMS-MS. J Am Soc Mass Spectrom 18, 1249-1264 (2007)

40. Matz, L.M., Dion, H.M., Hill Jr., H.H.: Evaluation of Capillary Liquid Chromatography-Electrospray Ionization Ion Mobility Spectrometry with Mass Spectrometry Detection. J Chromatogr A 946, 59-68 (2002)

41. Lee, Y.J., Hoaglund-Hyzera, C.S., Barnes, C.A.S., Hilderbrand, A.E., Valentine, S.J., Clemmer, D.E.: Development of High-Throughput Liquid Chromatography Injected Ion Mobility Quadrupole Time-ofFlight Techniques for Analysis of Complex Peptide Mixtures. $J$ Chromatogr B 782, 343-351 (2002)

42. Eckers, C., Laures, A.M., Giles, K., Major, H., Pringle, S.: Evaluating the Utility of Ion Mobility Separation in Combination with HighPressure Liquid Chromatography/Mass Spectrometry to Facilitate Detection of Trace Impurities in Formulated Drug Products. Rapid Commun Mass Spectrom 21, 1255-1263 (2007)

43. Eiceman, G.A., Karpas, Z.: Ion Mobility Spectrometry, 2nd edn. CRC Press, Boca Raton (2005)

44. Mazzeo, J.R., Neue, U.D., Kele, M., Plumb, R.S.: Advancing LC Performance with Smaller Particles and High Pressure. Anal Chem 77, 460A-467A (2005)

45. Wu, N., Clausen, A.M.: Fundamental and Practical Aspects of Ultrahigh Pressure Liquid Chromatography for Fast Separations. J Sep Sci 30, 1167-1182 (2007)

46. Chen, S.J., Kord, A.: Theoretical and Experimental Comparison of Mobile Phase Consumption between Ultra-High-Performance Liquid Chromatography and High Performance Liquid Chromatography. $J$ Chromatogr A 1216, 6204-6209 (2009)

47. Polybrominated Diphenyl Ethers (PBDEs) Project Plan. U.S. Environmental Protection Agency. March 2006.

48. Liu, Z., Patterson, D.G.: Geometric Approach to Factor Analysis for the Estimation of Orthogonality and Practical Peak Capacity in Comprehensive Two-Dimensional Separations. Anal Chem 67, 3840-3845 (1995) 